\title{
Next-Generation Composite Coating System: Nanocoating
}

\author{
Weiwei Bao, Zhifeng Deng, Shaodan Zhang, Zhuoting Ji and Haichang Zhang* \\ School of Materials Science and Engineering, Shaanxi University of Technology, Hanzhong, China
}

Nanocoating combines the protective properties of conventional coating system with effects on nanoscale such as high hardness, UV scattering, and uniform dispersing. Their facile and low-cost synthesis, together with superior protective properties and multi-functionalities, makes nanocoating attractive candidates for next-generation coating systems. In this review, a brief introduction regarding mainstream nanocoating and its related challenges including the zinc oxide-, titanium dioxide-, silica dioxide-, graphene-, carbon nanotube-based nanocoating system is presented. Finally, a perspective of the nanocoating is demonstrated.

Keywords: corrosion resistance, protection, nanocoating, nanoparticle, coating system

\section{OPEN ACCESS}

Edited by:

Flavio Deflorian,

University of Trento, Italy

Reviewed by:

Changdong Gu,

Zhejiang University, China

Santiago Fajardo,

Centro Nacional De Investigaciones Metalurgicas (CENIM), Spain

*Correspondence:

Haichang Zhang

haichangzhang@hotmail.com

Specialty section:

This article was submitted to Environmental Materials,

a section of the journal

Frontiers in Materials

Received: 25 February 2019 Accepted: 01 April 2019 Published: 17 April 2019

Citation:

Bao W, Deng Z, Zhang S, Ji Z and Zhang H (2019) Next-Generation Composite Coating System:

Nanocoating. Front. Mater. 6:72. doi: 10.3389/fmats.2019.00072

\section{INTRODUCTION}

Nanocoating is defined as having either the thickness of the coating or the second phase particles that are dispersed into the matrix in the nanosized range, which is a trend in the application of nanotechnology for the prevention and control of corrosion. This technology is growing rapidly in the field of corrosion protection and wear resistance of steel substrate materials compared to conventional coating (Bugnicourt et al., 2016). Conventional coating, organic, or inorganic coating, have been widely applied for the protection of metals against corrosion, which has made significant progress in recent years. However, despite significant improvements in coating technologies, problems continue in the long-term protection of metal from aggressive environments (Søresen et al., 2009). For the purpose of addressing this issue, the introduction of nanoparticles, nanocomposites, or nanocontainers in the coating formulation has been developed to enhance the wear resistance, shock, or pressure resistance and improve thermal conductivity of offshore structures, vessels, and drilling equipment (Müler et al., 2017). In addition, nanomaterials in the coating system can enable coating with superhydrophobic performance which endows the nanocoating with multi-functionalities such as anti-corrosions, anti-icing, and anti-fogging etc., (Das et al., 2018). Since nanocoating equips the substrate with special functions, the key results of nanocoating are summarized in several good reviews (Bugnicourt et al., 2016; Müler et al., 2017; Das et al., 2018). However, a comprehensive overview of nanocoating, with special emphasis on the distinct nano-pigment systems and their challenges, has not been yet thoroughly covered by the recent report.

In this review, we will briefly introduce mainstream nanocoating, its related challenges and applications including the zinc oxide $(\mathrm{ZnO})$-, titanium dioxide $\left(\mathrm{TiO}_{2}\right)$-, silica dioxide $\left(\mathrm{SiO}_{2}\right)$-, graphene-, and carbon nanotube (CNT)-based nanocoating system. Finally, our perspective on the potential further development trends for the next generation nanocoating is provided. 


\section{DISTINCT NANOCOATING SYSTEM}

\section{ZnO-Based Nanocoating}

Nanocoating systems provide corrosion protection of metallic substrates via barrier effect, inhibitive effect, or anodically active metal effect (galvanic effect) (Müler et al., 2017). The Znbased nanocoating protective mechanism belongs to one of the galvanic effects, in which it sacrificially corrodes by the oxygen and moisture from the coating surface and forms a corrosion product such as $\mathrm{ZnO}$. This corrosion product provides protection similar to a barrier effect. Recently, Ramezanza et al. reported different proportion of $\mathrm{ZnO}$ nanoparticles $(0,2,3.5,5$, and 6.5 wt\%) into the epoxy-polyamide coating (Ramezanzadeh et al., 2011). The studies showed that the physical interaction between the nanoparticles and coatings resulted in improved resistance against hydrolytic degradation in comparison with the blank epoxy coating. In addition, introducing $\mathrm{ZnO}$-nanoparticles into the coating system could increase the coating curing degree resulting in the $\mathrm{ZnO}$-based nanocoating with lower curing enthalpy. When adding the $\mathrm{ZnO}$ nanoparticles, the barrier properties of the coating has been significantly improved due to the increasing crosslinking density of the coating and the formation of corrosion product. The nanocoating with the best barrier properties was observed with $\mathrm{ZnO}$ composite of $3.5 \%$. Once the $\mathrm{ZnO}$ nanoparticles were increased above 3.5\% volume concentration, the barrier properties, typically the corrosion resistance, was decreased due to the wreaked crosslinking density and the high loading aggregations. Another reason might be that the amount of resin was insufficient to wet all the pigments; therefore, the coating did not form a continuous film, which resulted in extensive defects throughout the coating. When constructing $\mathrm{ZnO}$-based nanocoating, the size of $\mathrm{ZnO}$ particles considerably affects the nanocoating anticorrosion properties. $\mathrm{ZnO}$ particles with $20 \mathrm{~nm}$ in the polyurethane coatings showed better protective performance than that of the ones with $400 \mathrm{~nm}$ (Yang et al., 2005). This could be explained by the fact that small size particles have greater surface activity, such as borders and corners, which can absorb more resin on their surfaces.

Except enhancing the anticorrosion properties, nano- $\mathrm{ZnO}$ in the coating could also improve its UV resistance. When exposing alkyd-based water borne coating under UV-radiation for $110 \mathrm{~h}$, there were several cracks and pinholes on the surface, while for the $\mathrm{ZnO}$-based nanocoating under the same condition, no cracks were observed (Dhoke et al., 2009). Nano-ZnO particles, typically between 20 and $40 \mathrm{~nm}$, could scatter UV radiation between 200 and $400 \mathrm{~nm}$, thereby providing good UV blocking property to the coating system without interacting with the UV radiation. It should be noticed that the size of the nanoparticles plays a key role in enhancing the UV resistance.

The oxygen and water were the main reasons that caused the metal materials to corrode. Thus, the development of superhydrophobic coating, which has nearly non-wetting results with easy rolling of water droplets from the surface, is of utmost important. Superhydrophobic coating with water contact angle (WCA) $>150^{\circ}$ and sliding angle (SA) $<10^{\circ}$ are often difficult to be obtained. Introducing modified nano$\mathrm{ZnO}$ particles into the coating is a simple and inexpensive approach to obtain superhydrophobic coating (Das et al., 2018). Traditionally pure nano- $\mathrm{ZnO}$ are hydrophilic due to many hydroxyl groups existing on its surface (Qing et al., 2015). Modification the nano- $\mathrm{ZnO}$ particles with stearic acid obtaining hydrophobic nano-ZnO was reported by Qing et al. (2015). Using the modified nano- $\mathrm{ZnO}$ particles to construct fluorinated polysiloxane (FPDHS) nano- $\mathrm{ZnO}$ nanocoating showed superhydrophobicity with WCA as high as $166^{\circ}$ Figure 1a), while the pure FPDHS coating exhibited hydrophobicity with WCA of only $143^{\circ}$. Recently, various approaches to develop superhydrophobic $\mathrm{ZnO}$-based nanocoating have been reported, such as using polydimethylsioxane, hexadecyltrimethoxysilane, and aminopropyltriethoxysilane etc., (Wu et al., 2005; Chakradhar et al., 2011; Li et al., 2015; Velayi and Norouzbeigi, 2018). Appropriate modification ZnOnanoparticles can not only enhance the coating hydrophobicity, but also increase its corrosion resistance, for instance the corrosion rate of modified $\mathrm{ZnO}$-based nanocoating showed 11fold decrease compared to the pure coating. When constructing superhydrophobic nanocoating, it should be noticed that the coating superhydrophobic improved with the increase in surface roughness, meanwhile introducing small size and appropriate amount of nanoparticles is quite important for forming high surface roughness.

\section{$\mathrm{SiO}_{2}$-Based Nanocoating}

Silicon dioxide, one of the most complex and most abundant families of materials, exists as a synthetic product and as a compound of several minerals. The first commercial-grade surface-modified silica nanoparticles were produced into market in 2002, which were introduced into the epoxy resin by a modified sol-gel process and had a very narrow particle size distribution (Sprenger, 2013). Many metal-O-Si bonds were generated on the surface of substrate, which provided not only the supplement of the good physical barrier effect, but also the improvement of adhesion force between coating and substrate. Silica with inherent strong hardness and resistance against chemicals and alteration characteristics allow the nano$\mathrm{SiO}_{2}$ particles in coatings to improve various properties such as modulus, stiffens, toughness, scratch resistance, and anticorrosions. Conradi et al. presented a $0.5 \mathrm{~kg}$ load on the surface of the pure epoxy and $130 \mathrm{~nm} \mathrm{SiO}_{2}$ /epoxy coating, separately, which showed the indents in the epoxy coating were significantly large compared to those in the $\mathrm{SiO}_{2}$ /epoxy coating, and the hardness was enhanced by almost 40\% (Conradi et al., 2013). Improvement of the Vickers hardness could be due to the strong hardness of Nano- $\mathrm{SiO}_{2}$ into the coatings considerably affected the morphology, the area roughness parameters $S_{a}$ from 16 to $329 \mathrm{~nm}$. This further influenced the surface hydrophobicity with the WCA from $84.6^{\circ}$ to $94.2^{\circ}$. The hydrophobicity affected by the surface roughness could be due to trapped air between the surface and the water droplet, which can minimize the contact area by creating micro/nano structures. Improved hydrophobicity resulted in the nano- $\mathrm{SiO}_{2}$ /epoxy coating with enhanced anticorrosion effect.

As discussed in section $\mathrm{ZnO}$-Based nanocoating, coating hydrophobicity plays a key role in the anti-corrosion, hence 


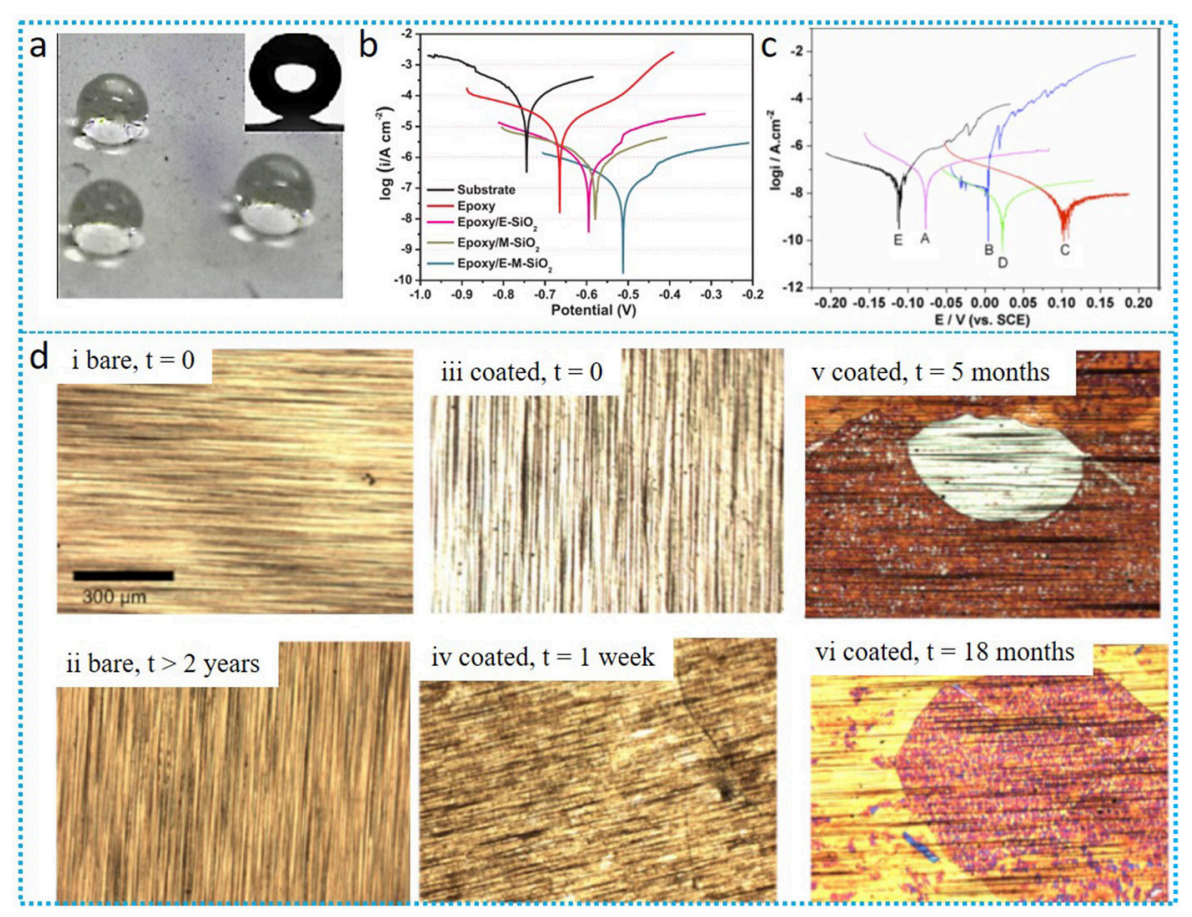

FIGURE 1 | (a) Image of water droplets on the modified-ZnO/FPDHS superhydrophobic surface (Qing et al., 2015); (b) The polarization curves of bare substrate and all coating system based on $\mathrm{SiO}_{2}$-nanocoating after the immersion of 80 days (Ye et al., 2018); (c) polarization curves for pure TiO $2 / 316$ (A), $\mathrm{Cl}-\mathrm{TiO} / 316 \mathrm{~L}$ (B), $\mathrm{N}-\mathrm{TiO}_{2} / 316 \mathrm{~L}(\mathrm{C}), \mathrm{S}-\mathrm{TiO}_{2} / 316 \mathrm{~L}$ and bare $316 \mathrm{~L}$ coating (E) in $0.5 \mathrm{M} \mathrm{NaCl}$ solution (Yun et al., 2007); (d) image of graphene-covered Cu and bare Cu in ambient condition (Schriver et al., 2013).

modification nano- $\mathrm{SiO}_{2}$, resulting in the nanocoating with superhydrophobicity and improvement compatibility can significantly increase the nanocoating corrosion resistance. Very recently, Ye and colleagues compared the performance of different nano- $\mathrm{SiO}_{2}$ based coating systems such as electrodeposited oligoaniline modified silica/epoxy coating $\left(\mathrm{E}-\mathrm{M}-\mathrm{SiO}_{2}\right)$ and electrodeposited pure silica coating/epoxy $\left(\mathrm{E}-\mathrm{SiO}_{2}\right)$. The E-M- $\mathrm{SiO}_{2}$ coating exhibited superhydrophobicity with WCA of $167^{\circ}$, while $\mathrm{E}^{-} \mathrm{SiO}_{2}$ exhibited hydrophobicity with WCA of $143.5^{\circ}$ (Ye et al., 2018). Superhydrophobicity could availably inhibit the diffusion of corrosive medium, hence $\mathrm{E}-\mathrm{M}-\mathrm{SiO}_{2}$ coating showed better corrosion protection compared to $\mathrm{E}-\mathrm{SiO}_{2}$. The author also compared the performance between E-M-SiO ${ }_{2}$ with sol-gel oligoaniline modified silica/epoxy coating $\left(\mathrm{M}-\mathrm{SiO}_{2}\right)$, in which the $\mathrm{E}-\mathrm{M}-\mathrm{SiO}_{2}$ showed better hydrophobicity and corrosion protection performance (Figure 1b). This could be due to most silica coating obtained by sol-gel approach with low surface roughness, which seriously restricts the thickness of coating, thereby the physical barrier of pre-process coating was weak.

For conventional coating, there is no protective effect once it is damaged, protection only lasts for the first damage. Self-healing coatings, possessing the internal capability to repair sustained damage by themselves or with some outside stimulation, is in the trend due to its providing feedback active healing ability to a scratch on metal surfaces for long term protection. Introducing self-healing microcapsules, such as perfluorooctyl triethoxysilane-urea-formaldehyde (POT-UF) shell, ethanolamine-polystyrene (ETA-PS) shell or diethanolamine-polystyrene (DEA-PS) shell, into the modified nano-silica/epoxy nanocoating and enhancing the coating anti-corrosion performance was reported by Kongparakul's group (Kongparakul et al., 2017). Among all the three systems, the POT-UF shell microcapsules performed the best corrosion prevention due to the increased length of the diffusion pathways, as well as decreased the oxygen permeability of the coating. Other approaches, such as using nanocontainers, self-healing additive, layer-by layer deposition, etc. could also obtain self-healing nanocoating (Shchukin et al., 2006; Li et al., 2013). Hydrophobic coating is unstable and easy to lose its ability to resist water (Zhang et al., 2006). Hence, self-healing coating combined with superhydrophilicity behavior are promising due to its long-term protection properties.

\section{$\mathrm{TiO}_{2}$-Based Nanocoating}

Titanium dioxide, one of the most commonly occurring oxides of titanium, received a lot of attention due to its easily available, relatively inexpensive, chemical stability, and harmless nature which was widely applied in several fields such as paints, coatings, inks etc. (Munafò et al., 2015). Introducing nano- $\mathrm{TiO}_{2}$ into coating systems can lead the nanocoating with improvement protection and can even endow it with self-cleaning properties. Shen et al. reported that covering a uniform $\mathrm{TiO}_{2}$ nanoparticles films on the surface of $316 \mathrm{~L}$ stainless steel could sufficiently 
improve its corrosion resistance properties, the corrosion resistance increasing over three order of magnitudes (Shen et al., 2005). The protection mechanism of $\mathrm{TiO}_{2}$-based nanocoating is that electron and hole are generated in the coating once exposing nano- $\mathrm{TiO}_{2}$ to $\mathrm{UV}$-irradiation, in which the electrons transferred to the metal substrate thereby making its electrode potential more negative than its corrosion potential, meanwhile, $\mathrm{TiO}_{2}$ does not get consumed. Nano- $\mathrm{TiO}_{2}$-based coating is promising to protect metal with anti-corrosion. However, the protection mechanism suggests that pure $\mathrm{TiO}_{2}$ nanocoating cannot be used under dark conditions due to the photo effect. In addition, once small defects appear in the nanocoating, these nanocoating are no longer able to protect the exposed zone, which means the nanocoating works only until their surface is intact. Numbers of works attempt to address this issue through the modification nano- $\mathrm{TiO}_{2}$ coatings such as noble metal deposition, doping of metallic and non-metallic ions, etc. (Hoffmann et al., 1995; Park and Choi, 2004). Yun and colleagues reported $\mathrm{TiO}_{2}$-nanocoating without photo-effect using doped $\mathrm{TiO}_{2}$ with $\mathrm{N}, \mathrm{S}$, and $\mathrm{Cl}$ (Yun et al., 2007). Electrochemical polarization was conducted in $0.5 \mathrm{M} \mathrm{NaCl}$ solution under dark conditions for the different coating systems. Comparing this to the bare $316 \mathrm{~L}$, the pure $\mathrm{TiO}_{2}$-nanocoating slightly improved the corrosion-resistance, while the corrosionresistance performance for the dopant-modified $\mathrm{TiO}_{2}$ coating was significantly enhanced. This could be due to the eliminating photo effect of the modified nano- $\mathrm{TiO}_{2}$ coating (Figure 1c). Other research regarding modification nano- $\mathrm{TiO}_{2}$ particles improving the nanocoating corrosion resistance has also been reported, such as polypyrrole/Sn-doped $\mathrm{TiO}_{2}$, thermal oxidation, introducing polyaniline in the coating system etc. (Krishna and Sun, 2005; Radhakrishnan et al., 2009; Mahmoudian et al., 2011).

$\mathrm{TiO}_{2}$ is normally hydrophobic. However, once it is exposed under UV-illumination, it becomes both oleophilic and hydrophilic, which will decrease the organic liquid angle or WCA until there is almost complete flattening of organic liquids or water droplets on the surface. This property prevents the external dirty directly contacting the coating surface and allowing an easier removal of stain. Based on this performance, $\mathrm{TiO}_{2}$-based nanocoating as self-cleaning effect coating was widely used, such as on glass, stone, and photovoltaic module (Munafò et al., 2015). A single-layer (SL) and three-layer (ML) treatment nanocoating were obtained through spraying the nano- $\mathrm{TiO}_{2}$ product directly on the stone surface with different amounts obtained (Goffredo et al., 2013). Under UV illumination, there was no significant degradation of stains on untreated surfaces, while the photocatalytic degradation of the strain was very rapid for the SL and ML coating, the rhodamine B losing almost $50 \%$ of its original color after $4 \mathrm{~h}$. $\mathrm{TiO}_{2}$-based nanocoating are transparent, hence it can be applied directly on architectural surface for protection without altering their original aspect. Numbers of works on the $\mathrm{TiO}_{2}$ nanoparticles into different coating systems for optimizing its self-cleaning performance have been reported (Kaplani et al., 2015; Crupi et al., 2018). However, the analyses carried on the $\mathrm{TiO}_{2}$ self-cleaning efficiency up to now still lack a more complete approach. The system studied on the relationship between the self-cleaning and the size or amount of nano- $\mathrm{TiO}_{2}$, the further optimization of the nano- $-\mathrm{TiO}_{2}$ particles and extending the lifepath of the coating are still a challenge.

\section{Carbon (Graphene and Carbon Nanotube)-Based Nanocoating}

Nanoscale carbon, graphene and CNT, are potential useful applications as nanocoating in materials protection due to its inherent characters, such as the high stiffness and conductivity capacity (Hu et al., 2014). Chen et al. first time successfully used as-grown graphen to protect the surface of metallic growth substrate of $\mathrm{Cu}$ or $\mathrm{Cu} / \mathrm{Ni}$ alloy away from air oxidation (Chen et al., 2011). The covered graphene resulted in a passivation of metal underneath, which offered an inserted block between the reactants and the protected metal. Except the oxidation resistance, graphene-based nanocoating could also effectively extend materials thermal stability and corrosion-resistance. Kwon et al. used graphene and metal-chloride-doped graphene over layers on 25 um thick copper foil, in which the chlorine evaporation was almost blocked, and maintained the doped state even after thermal annealing (Kwon and Kim, 2014). Yu and coworkers introduced graphene, typically metronidazole modified graphene oxide, on the metal surface which exhibited better corrosion resistance than the bare metal (Yu et al., 2016).

It should be noticed that graphene offers an impressive oxidation barrier for the short-term, however, for long-term scales, graphene promoted the metal corrosion instead of preventing it. Schriver et al. compared the sample surfaces between bare $\mathrm{Cu}$ and graphene-coated $\mathrm{Cu}$ under ambient conditions for up to 2 years (Schriver et al., 2013). The results showed that slight color changing happened for the bare $\mathrm{Cu}$ after 2 years. For the graphene-protected $\mathrm{Cu}$, it was shiny and free of oxide within 1 week. However, the surface stared to tarnish non-uniformly with small patches after 1 month, which gradually caused high oxide after 5 months. Finally heavy oxidization on virtually all of the surface was observed at 18 months (Figure 1d). Non-uniform oxidation or defects of graphene will lead to stress and cracking of the oxidation layer, which often opens a new avenue for corrosion. In addition, the monolayer graphene often exhibited wetting transparency (Hu et al., 2014). These characteristics result in monolayer graphene with bad protection properties. To address this issue, multi-layered graphene or nanocomposite such as mixture with epoxy were used, which showed good protective performance (Rafiee et al., 2012; Tang et al., 2013). Yang et al. studied epoxy coating on a copper substrate modified by fluorographene nanosheet, which showed superhydrophobicity with WCA up to $154^{\circ}$ (Yang et al., 2017). The superhydrophobicity characteristic of this nanocoating was ascribed to the irregular microstructure constructed by randomly stacked fluorographene.

CNT, allotropes of graphene, was used in coating effect protection performance typically on the anti-oxidation and corrosion resistance. Recent studies showed the CNT-based nanocoating exhibited similar protection performance as graphene-based nanocoating (Janas and Koziol, 2013). In many cases, the CNT not only acts as a physical barrier to the corrosion 
process, but also improves the electrochemical properties to anti-oxidation (Ates, 2016). Epoxy composite coatings filled with different multiwalled CNT contents was reported by Frankel's group, which indicated that multiwalled CNT can influence the coating performance such as improvement adhesion strength, increasing wear resistance and the total impedance enhancement (Khun et al., 2013). Nanocoating containing modified CNT composite should be in the trend.

\section{CONCLUSION AND PERSPECTIVES}

The ever-growing interest in nanocoating and its fascinating protective properties makes it a promising candidates for nextgeneration protecting system. In this review, we have given an overview of the recently popular composite nanocoating system based on $\mathrm{ZnO}, \mathrm{SiO}_{2}, \mathrm{TiO}_{2}$, grapheme, and CNT. On the basis of the literature findings above, it is noticeable that introducing the modified-nanoparticles into the conventional coating system could significantly improve the coating protective characters, typically the corrosion-, UV-, and oxidationresistance performance, and even self-cleaning functionality. However, the amount of introduced nanoparticles should be proper, otherwise, it will reduce the protective properties. When using a carbon-based nanocoating system, it should be the CNT or graphene modification, or compositing it with other coating systems to extend its corrosion resistance.

\section{REFERENCES}

Ates, M. (2016). A review on conducting polymer coatings for corrosion protection. J. Adhhes. Sci. Technol. 30, 1510-1536. doi: 10.1080/01694243.2016.1150662

Bugnicourt, E., Kehoe, T., Latorre, M., Serrano, C., Philippe, S., and Schmid, M. (2016). Recent prospects in the inline monitoring of nanocomposites and nanocoating by optical technologies. Nanomaterials 6:150. doi: 10.3390/nano6080150

Chakradhar, R. P. S., Kumar, V., Dinesh, R. J. L., and Basu, B. J. (2011). Fabrication of superhydrophobic surfaces based on ZnO-PDMS nanocomposite coatings and study of its wetting behavior. Appl. Surf. Sci. 257, 8569-8575. doi: 10.1016/j.apsusc.2011.05.016

Chen, S., Brown, L., Levendorf, M., Cai, W., Ju, S. Y., Edgeworth, J., et al. (2011). Oxidation resistance of graphene-coated $\mathrm{Cu}$ and $\mathrm{Cu} / \mathrm{Ni}$ alloy. ACS Nano 5, 1321-1327. doi: 10.1021/nn103028d

Conradi, M., Kocijan, A., Kek-Merl, D., Zorko, M., and Verpoest, I. (2013). Mechanical and anticorrosion properties of nanosilicafilled epoxy-resin composite coatings. Appl. Surf. Sci. 292, 423-437. doi: 10.1016/j.apsusc.2013.11.155

Crupi, V., Fazio, B., Gessini, A., Kis, Z., Russa, M. F. L., Majolino, D., et al. (2018). $\mathrm{TiO}_{2}-\mathrm{SiO}_{2}$-PDMS nanocomposite coating with self-cleaning effect for stone material: finding the optimal amount of $\mathrm{TiO}_{2}$. Constr. Build. Mater. 166, 464-471. doi: 10.1016/j.conbuildmat.2018.01.172

Das, S., Kumar, S., Samal, S. K., Mohanty, S., and Nayak, S. K. (2018). A review on superhydrophobic polymer nanocoatings: recent development and applications. Ind. Eng. Chem. Res. 57, 2727-2745. doi: 10.1021/acs.iecr.7b04887

Dhoke, S. K., Khanna, A. S., and Sinha, T. J. M. (2009). Effect of nano-ZnO particles on the corrosion behavior of alkyd-based waterborne coatings. Prog. Org. Coat. 64, 371-382. doi: 10.1016/j.porgcoat.2008.07.023
Nanocoating with a wide branch of genuine properties has been intelligently used by the scientific community and industries. The future research on this field should be focus on further improving its protecting properties combined with multifunctionalities, such as self-cleaning, self-healing, UV-resistance, antibacterial, thermal resistance, color-changing in one single nanocoating. In addition, studies on the relationship between minimization of the size, optimization of the modification and the amount, uniform dispersion of the nanoparticles and the nanocoating performance are important, and finally development of a new nanocoating system. Furthermore, introducing organic nano-pigment or multi-different pigments into one coating system to enhance the coating properties is a growing trend.

\section{AUTHOR CONTRIBUTIONS}

All authors listed have made a substantial, direct and intellectual contribution to the work, and approved it for publication.

\section{FUNDING}

The authors acknowledge the support from the Natural Science Foundation of China, under Grant 21805151, the Natural Science Foundation of Shandong Province, China, under Grant ZR2018MB024, and Special Scientific Research Planned Projects of Education Department of Shaanxi Province (No. 17JK0161).

Goffredo, G. B., Quagliarini, E., Bondioli, F., and Munaf, Ò. (2013). $\mathrm{TiO}_{2}$ nanocoatings for architectural heritage: self-cleaning treatments on historical stone surfaces. Proc. Int. Mech. E Part N: J. Nanoeng. Nanosyst. 228, 1-9. doi: 10.1177/1740349913506421

Hoffmann, M. R., Martin, S. T., Choi, W., and Bahnemann, D. W. (1995). Environmental applications of semiconductor photocatalysis. Chem. Rev. 95, 69-96. doi: 10.1021/cr00033a004

Hu, J., Ji, Y., Shi, Y., Hui, F., Duan, H., and Lanza, M. (2014). A review on the use of graphene as a protective coating against corrosion. Annu. Mater. Sci. Eng. 1:16.

Janas, D., and Koziol, K. K. (2013). A review of production methods of carbon nanotube and graphene thin films for electrothermal applications. Nanoscale 6, 3037-3045. doi: 10.1039/c3nr05636h

Kaplani, K., Panayiotatos, Y., and Kaldellis, J. K. (2015). “TiO 2 -based nanocoating with self-cleaning and anti-reflective properties: effects on PV performance," in Photovoltaic Technical Conference-Advanced Materials and Processes to Innovative Applications, 2015-05-27-2015-05-29.

Khun, N. W., Troconis, B. C. R., and Frankel, G. S. (2013). Effects of carbon nanotube content on adhesion strength and wearand corrosion resistance of epoxy composite coatings on AA2024-T3. Prog. Org. Coat. 77, 72-80. doi: 10.1016/j.porgcoat.2013.08.003

Kongparakul, S., Kornprasert, S., Suriya, P., Le, D., Samart, C., Chantarasiri, N. C., et al. (2017). Self-healing hybrid nanocomposite anticorrosive coating from epoxy/modified nanosilica/perfluorooctyl triethoxysilane. Prog. Org. Coat. 104, 173-179. doi: 10.1016/j.porgcoat.2016.12.020

Krishna, D. S. R., and Sun, Y. (2005). Thermally oxidised rutile- $\mathrm{TiO}_{2}$ coating on stainless steel for tribological properties and corrosion resistance enhancement. Appl. Surf. Sci. 252, 1107-1116. doi: 10.1016/j.apsusc.2005.02.046

Kwon, K. C., and Kim, S. Y. (2014). Extended thermal stability in metal-chloride doped graphene using graphene overlayers. Chem. Eng. J. 244, 355-363. doi: 10.1016/j.cej.2014.01.100 
Li, G. L., Zheng, Z., Möhwalk, H., and Shchukin, D. G. (2013). Silica/polymer double-walled hybrid nanotubes: synthesis and application as stimuliresponsive nanocontainers in self-healing contings. ACS Nano 7, 2470-2478. doi: $10.1021 / \mathrm{nn} 305814 \mathrm{q}$

Li, S., Sun, Z., Li, R., Dong, M., Zhang, L. Qi, W. et al. (2015). ZnO nanocomposites modified by hydrophobic and hydrophilic silanes with dramatically enhanced tunable fluorescence and aqueous ultrastability toward biological imaging applications. Sci. Rep. 5:8475. doi: 10.1038/srep08475

Mahmoudian, M. R., Basirun, W., Alias J., and Ebadi, Y. (2011). Synthesis and characterization of polypyrrole/Sn-doped $\mathrm{TiO}_{2}$ nanocomposites (NCs) as a protective pigment. Appl. Surf. Sci. 257, 8317-8325. doi: 10.1016/j.apsusc.2011.03.075

Müler, K., Bugnicourt, E., Latorre, M., Jorda, M., Sanz, Y. E., Lagaron, J. M., et al. (2017). Review on the processing and properties of nanocoposites and nanocoating and their applications in the packing, automotive and solar energy fields. Nanomaterials 7:74. doi: 10.3390/nano7040074

Munafò, P., Goffredo, G. B., and Quagliarini, E. (2015). $\mathrm{TiO}_{2}$-based nanocoatings for preserving architectural stone surfaces: an overview. Constr. Build. Mater. 84, 201-218. doi: 10.1016/j.conbuildmat.2015.02.083

Park, J. S., and Choi, W. (2004). Enhanced remote photocatalytic oxidation of surface-fluorinated $\mathrm{TiO}_{2}$. Langmuir 20, 11523-11527. doi: 10.1021/la $048051 n$

Qing, Y., Yang, C., Hu, C., Zheng, Y., and Liu, C. (2015). A facile method to prepare superhydrophobic fluorinated polysiloxane/ZnO nanocomposite coatings with corrosion resistance. Appl. Surf. Sci. 326, 48-54. doi: 10.1016/j.apsusc.2014. 11.100

Radhakrishnan, S., Siju, S. R., Mahanta, D., Patil, S., and Madrs, G. (2009). Conducting polyaniline-nano- $\mathrm{TiO}_{2}$ composites for smart corrosion resistant coatings. Electrochim. Acta 54, 1249-1254. doi: 10.1016/j.electacta.2008.08.069

Rafiee, J., Gullapalli, H., Thomas, A. V., Yavari, F., Shi, Y., Ajayan, P. M., et al. (2012). Wetting transparency of graphene. Nat. Mater. 11, 217-222. doi: $10.1038 /$ nmat3228

Ramezanzadeh, B., Attar, M. M., and Farzam, M. (2011). A study on the anticorrosion performance of the epoxy-polyamide nanocoposites coating ZnO nanoparticles. Prog. Org. Coat. 72, 410-422. doi: 10.1016/j.porgcoat.2011. 05.014

Schriver, M., Regan, W., Gannett, W. J., Zaniewski, A. M., Crommie, M. F., and Zetti, A. (2013). Graphene as a long-term metal oxidation barrier: worse than nothing. ACS Nano 7, 5673-5678. doi: 10.1021/nn 4014356

Shchukin, D. G., Zheludkevich, M., Yasakau, K., Lamaka, S., Ferreira, M. G. S., and Möhwalk, H. (2006). Layer-by-layer assembled nanocontainers for self-healing corrosion protection. Adv. Mater. 18, 1672-1678. doi: 10.1002/adma.200502053

Shen, G. X., Chen, Y. C., and Lin, C. J. (2005). Corrosion protection of $316 \mathrm{~L}$ stainless steel by a $\mathrm{TiO}_{2}$ nanoparticle coating prepared by sol-gel method. Thin Solid Films 489, 130-136. doi: 10.1016/j.tsf.2005.05.016
Søresen, P., Kill, S., Johansen, D. K., and Weinell, C. (2009). Anticorrosive coating: a review. J. Coat. Technol. Res 6, 135-176. doi: 10.1007/s11998-008-9144-2

Sprenger, S. (2013). Epoxy resin composites with surface-modifed silicon dioxide nanoparticles: a review. J. Appl. Polym. Sci. 130, 1421-1428. doi: 10.1002/app.39208

Tang, L. C., Wan, Y. J., Yan, D., Pei, Y. B., Zhao, L., Li, Y. B., et al. (2013). The effect of graphene dispersion on the mechanical properties of graphene/epoxy composites. Carbon 60, 13-27. doi: 10.1016/j.carbon.2013.03.050

Velayi, E., and Norouzbeigi, R. (2018). Annealing temperature dependent reversible wettability switching of micro/nano structured $\mathrm{ZnO}$ superhydrophobic surfaces. Appl. Surf. Sci. 441, 156-164. doi: 10.1016/j.apsusc.2018.02.005

Wu, X., Zheng, L., and Wu, D. (2005). Fabrication of superhydrophobic surfaces from microstructured $\mathrm{ZnO}$-based surface via wet-chemical route. Langmuir 21, 2665-2667. doi: 10.1021/la050275y

Yang, L. H., Liu, F. C., and Han, E. H. (2005). Effects of P/B on the properties of anticorrosive coating with different particle size. Prog. Org. Coat. 53, 91-98. doi: 10.1016/j.porgcoat.2005.01.003

Yang, Z., Wang, L., Sun, W., Li, S., Zhu, T., Liu, W., et al. (2017). Superhydrophobic epoxy coating modified by fluorographene used for anti-corrosion and selfcleaning. Appl. Surf. Sci. 401, 146-155. doi: 10.1016/j.apsusc.2017.01.009

Ye, Y., Liu, Z., Liu, W., Zhang, D., Zhao, H., Wang, L., et al. (2018). Superhydrophobic oligoaniline-containing electroactive silica coating as preprocess coating for corrosion protection of carbon steel. Chem. Eng. J. 348, 940-951. doi: 10.1016/j.cej.2018.02.053

Yu, Z., Lv, L., Ma, Y., Di, H., and He, Y. (2016). Covalent modification of graphene oxide by metronidazole for reinforced anti-corrosion properties of epoxy coatings. RSC Adv. 6, 18217-18226. doi: 10.1039/C5RA23595B

Yun, H., Li, J., Chen, H. B., and Lin, C. J. (2007). A study on the N-, S- and $\mathrm{Cl}$-modified nano- $\mathrm{TiO}_{2}$ coatings for corrosion protection of stainless steel. Electrochim. Acta 52, 6679-6685. doi: 10.1016/j.electacta.2007.04.078

Zhang, J., Gu, C., Tong, Y., Yan, W., and Tu, J. (2006). A smart superhydrophobic coating on coating on AZ31B magnesium alloy with self-healing effect. Adv. Mater. Interfaces 3:1500694. doi: 10.1002/admi.201500694

Conflict of Interest Statement: The authors declare that the research was conducted in the absence of any commercial or financial relationships that could be construed as a potential conflict of interest.

Copyright (c) 2019 Bao, Deng, Zhang, Ji and Zhang. This is an open-access article distributed under the terms of the Creative Commons Attribution License (CC BY). The use, distribution or reproduction in other forums is permitted, provided the original author(s) and the copyright owner(s) are credited and that the original publication in this journal is cited, in accordance with accepted academic practice. No use, distribution or reproduction is permitted which does not comply with these terms. 